\title{
Personalized correction of lipid metabolism in blood of inhabitants of the metropolis under high technogenic load
}

\author{
Andrew K. Martusevich ${ }^{1, *}$, Konstantin A. Karuzin ${ }^{2}$
}

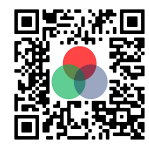

Use your smartphone to scan this QR code and download this article

\section{${ }^{1}$ Privolzhsky Research Medical University, Nizhny Novgorod, Russia \\ ${ }^{2}$ Bioniq Health-Tech Solutions Ltd., London, United Kingdom \\ Correspondence}

Andrew K. Martusevich, Privolzhsky Research Medical University, Nizhny Novgorod, Russia

Email: cryst-mart@yandex.ru

History

- Received: Apr 30, 2020

- Accepted: Jun 08, 2020

- Published: Jun 26, 2020

DOI : 10.15419/bmrat.v7i6.611

\section{Check for updates}

\section{Copyright}

(c) Biomedpress. This is an openaccess article distributed under the terms of the Creative Commons Attribution 4.0 International license.

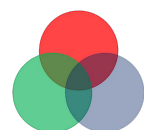

BioMedPress

The Open Access Publisher

\begin{abstract}
Introduction: The purpose of the study was to evaluate the effectiveness of personalized correction of violations of fat metabolism when using an individually prescribed vitamin and mineral complex. Methods: The study included 313 volunteers who belong to the category of "practically healthy people" and do not have a severe chronic pathology. All participants in the study were randomly assigned to the main group $(n=197)$ and the comparison group $(n=116)$. At the first stage, the state of blood lipid metabolism was evaluated in the representatives of both formed groups, and the laboratory examination complex included: determination of the total cholesterol concentration, the concentration of low- and high-density lipoprotein cholesterol, and the level of triglycerides. Patients of the main group were additionally monitored for the level of blood trace elements and a wide range of biochemical parameters. Taking into account the results of the latter, the composition of the vitamin and mineral complex was individually selected for them. The duration of its daily intake for all members of the main group was 60 days. Patients in the comparison group received a placebo for a similar time period. Result \& Conclusion: The study of the effectiveness of the personalized vitamin and mineral complex allowed us to demonstrate the positive effect of daily intake (for 2 months) on the parameters of blood lipid metabolism. It was manifested in a decrease in the total concentration of cholesterol, which was mainly provided by a decrease in the level of cholesterol contained in low-density lipoproteins.
\end{abstract}

Key words: lipid metabolism, blood, vitamine and mineral complexes, personalization

\section{INTRODUCTION}

There is an extremely high prevalence of significant lipid metabolism disorders in the modern population $^{1-4}$, which later serve as one of the main reasons for the formation and progression of cardiovascular and cerebrovascular pathology, obesity, metabolic syndrome, and other ailments. Chronic shifts in fat metabolism indicators are currently considered to be predictor of an unfavorable course and other pathogenetic disorders unrelated to dyslipidemia (e.g. diabetes mellitus, hypo- and hyperthyroidism, etc. $)^{1,5-8}$. Epidemiological studies carried out with the involvement of various groups of people, including those belonging to the category of "practically healthy persons", have allowed us to establish certain findings. Notably, in a significant proportion of the examined individuals, the main laboratory markers of the state of lipid metabolism (e.g. total cholesterol, lowdensity lipoprotein cholesterol, and triglyceride concentration) are either at elevated levels or approaching them, remaining in the border quartile of the norm (Q4) $)^{4,5,8,9}$. This indicates a high latent risk of effective participation of dyslipidemia in the development of the above diseases, primarily with respect to the cardiovascular profile ${ }^{1,6,10,11}$.

Based on this, it is extremely important to choose the most effective and physiological ways to correct the observed disorders of fat metabolism ${ }^{1,3,8,11,12}$. Traditionally, the first recommendation for such a group of patients is to change the nature of nutrition ${ }^{13-15}$, but without pharmacological support, this measure does not always allow for the full leveling of the considered shifts in metabolic processes, especially if there are significant deviations of laboratory parameters from the age reference range $e^{8,10,13,16}$. In this situation, targeted and individualized pharmacological support is necessary ${ }^{12,15}$. At the same time, the potential specificity of metabolic shifts, taking into account the individual characteristics of the body, determines the feasibility of using a personalized approach for correction; however, there are currently no effective means to ensure that ${ }^{15-18}$.

To solve this problem, we have been creating and testing a system of individual metabolic correction for a number of years, based on preliminary extended monitoring of the metabolic and microelement status of the body, followed by the formation of the compo- 
sition of the vitamin and mineral complex and stepby-step monitoring of its effectiveness ${ }^{19,20}$. The expediency of this complex for restoring the body's mineral homeostasis has been shown ${ }^{21}$, but its effect on lipid metabolism has not been previously considered. In this regard, the purpose of the study was to evaluate the effectiveness of personalized correction of changes in fat metabolism when using an individually prescribed vitamin and mineral complex.

\section{MATERIAL — METHODS}

\section{Patients}

The study included 313 volunteers (19-54 years old) who belong to the category of "practically healthy people" and do not have any severe chronic pathology. All participants in the study were randomly assigned to the main group $(n=197)$ and the treatment group $(n=116)$. The full design of our survey is illustrated in Figure 1. The distribution of estimated persons by gender is also shown in Figure 1.

Inclusion criteria were:

- Age from 18 to 60 years;

- Absence of chronic and acute pathology;

- Informed consent to participate in the study.

\section{Exclusion criteria were:}

- Age under 18 years and over 60 years;

- Presence of chronic and acute pathology;

- Declination to participate in the study;

- Allergy to some components of the complex.

\section{Laboratory examination protocol}

At the first stage, the state of blood lipid metabolism was evaluated for the subjects of both groups. The laboratory examination complex included the following: determination of the total cholesterol concentration, the level of low-density and high-density lipoprotein cholesterol (Ch-LPLD and Ch-LPHD, respectively), and triglycerides. All parameters were determined using standard methods. Parameters of lipid metabolism were monitored before and immediately after the end of the full course of treatment (for the treatment group), with the comparison group as a control.

At the second stage, we calculated individual deltas (between second control point [after full course of complex/placebo intake] and first point [baseline before treatment course]) for each tested parameter. The group deltas of the parameters were calculated as the sum of the deltas of each patient in this group.

\section{Scheme of appointment of individual vita-} min and mineral complex

Patients of the treatment group were additionally monitored for the level of 23 blood trace elements $(\mathrm{Na}$, $\mathrm{K}, \mathrm{Ca}, \mathrm{Mg}, \mathrm{Fe}, \mathrm{Cu}, \mathrm{Zn}, \mathrm{Se}, \mathrm{Cd}, \mathrm{Pb}, \mathrm{Al}, \mathrm{Cr}, \mathrm{Li}, \mathrm{B}, \mathrm{Co}, \mathrm{Si}$, $\mathrm{Mn}, \mathrm{Mo}, \mathrm{As}, \mathrm{Ni}, \mathrm{Hg}, \mathrm{Sb}$, and $\mathrm{Ti}$ ) and a wide range of biochemical parameters representing Fe metabolism, hepatic and intoxication makers, main hormones, and carbohydrate metabolism. Based on the results of this multiparametric laboratory examination, we formed the composition of a personal vitamin and mineral complex. The composition of the complex was supposed to replace the components of those metabolites for which the level was detected below or at the lower limit of the norm ${ }^{19,20}$. This method allowed us to select personalized components of the complex.

The duration of the daily intake of the complex for all members of the treatment group was 60 days. Patients in the comparison group received a placebo for a similar time period.

\section{Statistics}

The results were processed using the Statistica 6.0 program $^{22}$. All the data were processed with standard algorithms of descriptive statistics and were presented as Mean \pm SD. The dynamics of indicators were studied in two ways: by calculating the average values for the group and by using "individual deltas" (differences in indicators) separately for each subject.

\section{RESULTS}

It is known that the total cholesterol level is an integral indicator that characterizes the state of lipid metabolism. Analysis of the dynamics of this parameter allows us to establish that there were shifts in the concentration of total cholesterol in the second control point, but the severity of each was not the same (Figure 2). For example, in the treatment group who received a vitamin-mineral complex during the month, these changes were statistically significant (5.26 vs. $5.03 \mathrm{mmol} / \mathrm{l} ; \mathrm{p}<0.05$ in relation to the first control point). On the contrary, the comparison group showed a decrease in the parameter level only at the trend level $(5.26 v s .5 .07 \mathrm{mmol} / \mathrm{l} ; \mathrm{p}<0.1$ relative to the initial level).

In this regard, an illustrative estimate of the average individual deltas was made in addition to the standard statistical approach. On its basis, it was found that in the treatment group the average value of individual deltas was $-0.33 \mathrm{mmol} / \mathrm{l}(\mathrm{p}<0.05)$, and in the comparison group, the value was only $-0.12 \mathrm{mmol} / \mathrm{l}$ $(\mathrm{p}>0.1)$. 


\section{F $\mathrm{CONSORT}$}

CONSORT 2010 Flow Diagram

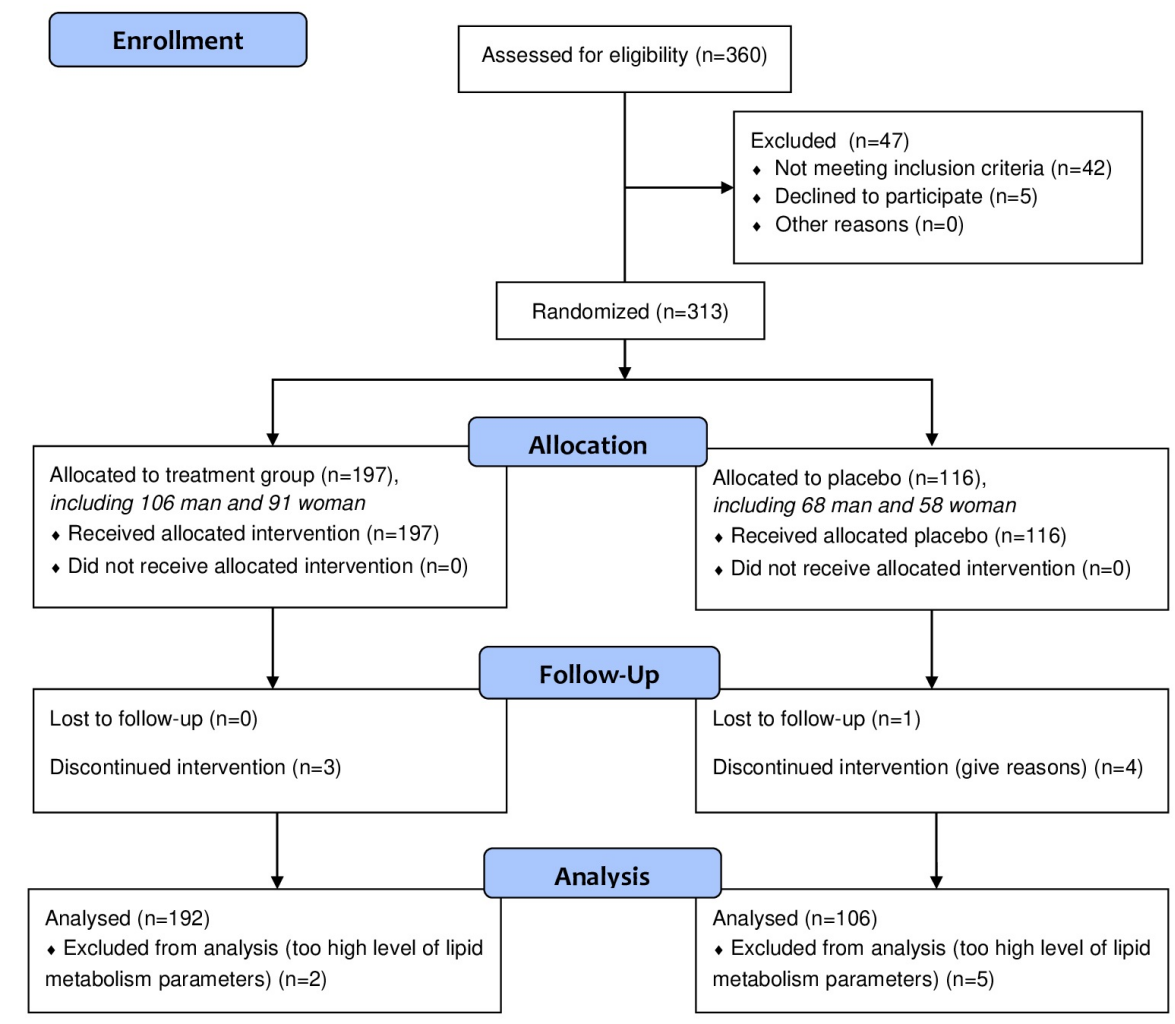

Figure 1: Design scheme for our study (as CONSORT 2010 Flow Diagram).

Similar dynamics were observed for low-density lipoprotein cholesterol (Figure 3). According to this parameter, a statistically significant decrease was found in the treatment group (3.28 vs. 3.10; $\mathrm{p}<0.05$ relative to the first control point), and there were no significant changes in the placebo subjects (3.28 vs. $3.22 ; \mathrm{p}>0.1)$. This indicates a positive transformation of the state of lipid metabolism since the reduction of total cholesterol is directly provided by reducing the most atherogenic fraction of cholesterol contained in low-density lipoproteins. We can assume that similar dynamics can be observed for very lowdensity lipoproteins and chylomicrons, but these indicators were not considered in this study. In contrast, there were no statistically significant shifts in cholesterol included in the fraction of high-density lipoprotein (1.48 vs. 1.44 and 1.48 vs. 1.43 for treatment and comparison groups, respectively).

The above trends were implemented to assess the individual deltas of the parameters, as shown in Figure 4. In particular, for low-density lipoprotein cholesterol in the treatment group, this criterion was equal to $0.26 \mathrm{mmol} / \mathrm{l}(\mathrm{p}<0.05)$, while in the treatment group it was $-0.06 \mathrm{mmol} / \mathrm{l}(\mathrm{p}>0.1)$. All of the above indicates the presence of positive changes in the concentration of cholesterol contained in low-density lipoproteins. It should be noted that in terms of low-density lipoprotein cholesterol and triglycerides, there were 


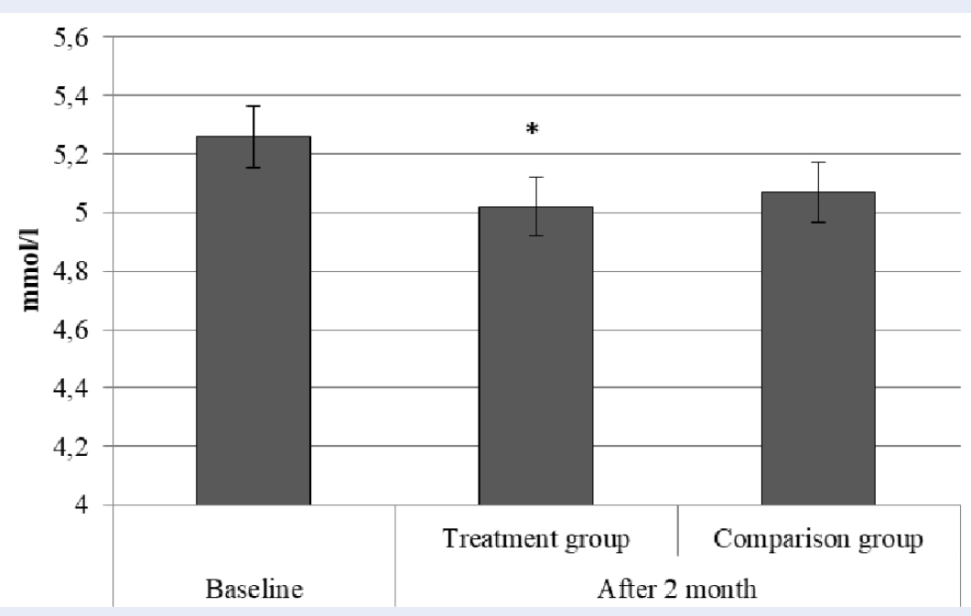

Figure 2: Plasma level of total cholestrol in dymamics of the use of vitamine and mineral complex (treatment group) vs. placebo (astericks indicates the presence of statistically valued differences to baseline level, $p<0.05)$.

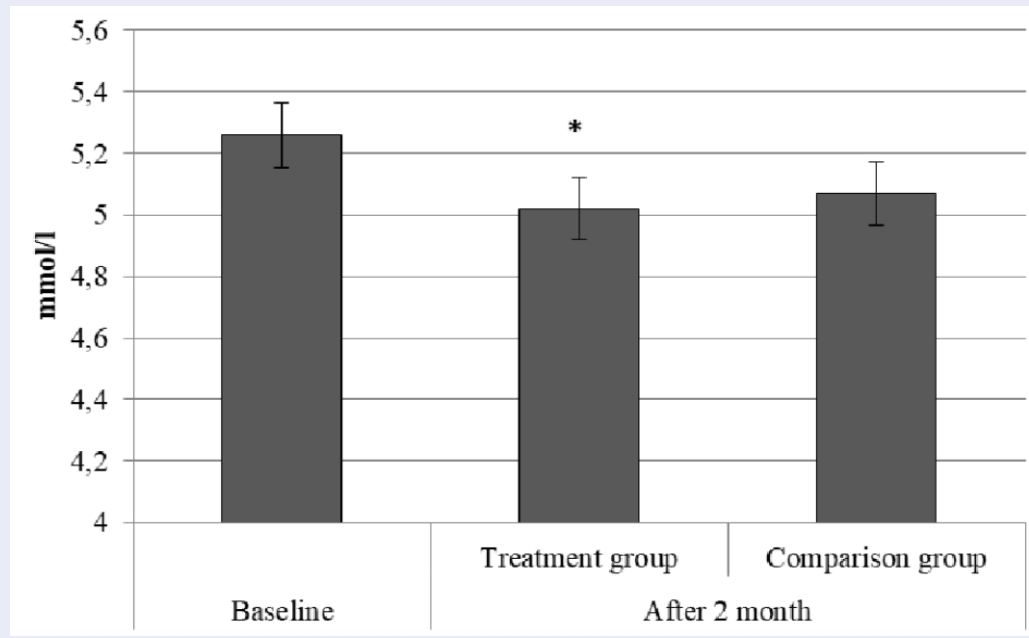

Figure 3: Plasma level of cholesterol in lipoproteins of high and low density (Ch-LPHD and Ch-LPLD, respectively) in dynamics of the use of vitamin and mineral complex (treatment group) vs. placebo (comparison group) (asterisks indicates the presence of statistically valued differences to baseline level, $p<0.05$ ).

no significant variations in both the treatment group and the comparison group.

Such dynamics indicates that the volunteers who received the vitamin-mineral complex have a moderate but significant restructuring of lipid metabolism, which consists in reducing the atherogenic fraction of cholesterol. These indicators characterize the integral shifts in metabolism that are formed as a result of the indirect effect of the studied complex (lipid components were not included in the composition of the applied complex) ${ }^{19}$.

\section{DISCUSSION}

Given the high prevalence of cardiovascular pathology and metabolic disorders, timely and complete correction of lipid metabolism shifts play a significant role in the primary and secondary prevention of cardiovascular incidents, which are important even for a cohort of people belonging to conditionally "practically healthy" individuals $1,6,11,17$. At the same time, it is important to emphasize that standard means of pharmacological correction ${ }^{3,7,10,23}$, i.e. the first line of which is carried, in particular statins ${ }^{5,8,24}$, are usually prescribed in the presence of pronounced vio- 


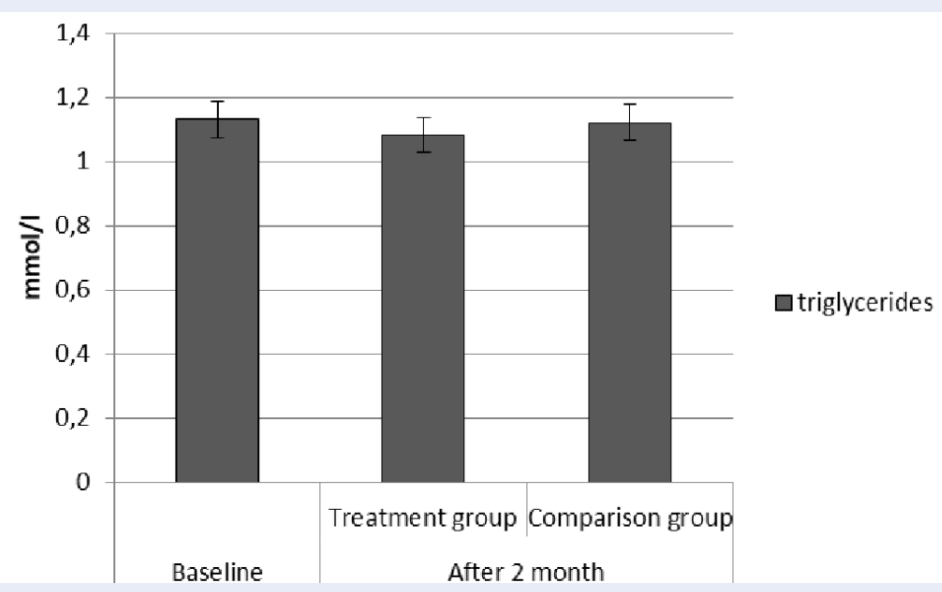

Figure 4: Plasma level of triglycerides in dynamics of the use of vitamin and mineral complex (treatment group) vs. placebo (comparison group) (asterisks indicates the presence of statistically valued differences to baseline level, $p<0.05)$.

lations of lipid metabolism. However, for moderate shifts or borderline indicators, the corrections are limited to dietary recommendations ${ }^{14-16,23,24}$. It is the disclosure of the optimization possibilities of the latter case that concerns our study. We demonstrated that the individualized administration of the vitamin-mineral complex according to the developed algorithm (after a preliminary extended laboratory examination of the patient ${ }^{19,20}$ ) helped to reduce both the total concentration of cholesterol and its pro-atherogenic fraction contained in low-density lipoproteins. It should be noted that this effect is indirect since the complex does not include components that directly affect fat metabolism. Therefore, the revealed positive effect of the studied vitamin and mineral complex is due to non-specific normalization of metabolism, in general.

The remaining integral parameters of lipid metabolism, including the concentration of triglycerides and high-density lipoproteins, were initially within the limits of the physiological norm, and not approaching the boundary values. In our opinion, this causes the absence of significant changes in their concentration at the end of the course of taking the complex.

The main limitations of our study were the limited location of the study and the need to conduct the research on a larger sample size, with the study repeated at least twice.

\section{CONCLUSION}

The study of the effectiveness of the personalized vitamin and mineral complex allowed us to demonstrate the positive effect of its daily intake (for 2 months) on the parameters of blood lipid metabolism. The vitamin-mineral complex treatment course led to a decrease in the total concentration of cholesterol, which mainly resulted from the decrease in the level of cholesterol contained in low-density lipoproteins.

\section{ABBREVIATIONS}

Ch-LPHD: cholesterol in lipoproteins of high density Ch-LPLD: cholesterol in lipoproteins of low density Q4: fourth quartile

\section{ACKNOWLEDGMENTS}

Not applicable.

\section{AUTHOR'S CONTRIBUTIONS}

A.K.M. and K.A.K. contributed to the conceptualization and design of the study, the acquisition, analysis and interpretation of data. They were drafting the article and revising the article critically for important intellectual content. All authors read and approved the final manuscript.

\section{FUNDING}

This article had no financial support of this faculty.

\section{AVAILABILITY OF DATA AND MATERIALS}

Data and materials used and/or analyzed during the current study are available from the corresponding author on reasonable request. 


\section{ETHICS APPROVAL AND CONSENT TO PARTICIPATE}

This study was conducted in accordance with the amended Declaration of Helsinki. The study was approved by Local Ethic Committee of Burnazyan's Medical Biophysical Center, and all participants provided written informed consent.

\section{CONSENT FOR PUBLICATION}

Not applicable.

\section{COMPETING INTERESTS}

The authors declare that they have no competing interests.

\section{REFERENCES}

1. Breuer HW. Hypertriglyceridemia: a review of clinical relevance and treatment options: focus on cerivastatin. Curr Med Res Opin. 2001;17(1):60-73. PMID: 11464448. Available from: https://doi.org/10.1185/0300799039117028.

2. Kones R. Molecular sources of residual cardiovascular risk, clinical signals, and innovative solutions: relationship with subclinical disease, undertreatment, and poor adherence: implications of new evidence upon optimizing cardiovascular patient outcomes. Vasc Health Risk Manag. 2013;9:617-670. PMID: 24174878. Available from: https://doi.org/10.2147/ VHRM.S37119.

3. Parhofer KG. The treatment of disorders of lipid metabolism. Dtsch Arztebl Int. 2016;113(15):261-268. PMID: 27151464 Available from: https://doi.org/10.3238/arztebl.2016.0261.

4. Tenenbaum A, Fisman EZ. "If it ain't broke, don't fix it": a commentary on the positive-negative results of the ACCORD Lipid study. Cardiovasc Diabetol. 2010;15(9):24. PMID: 20550659. Available from: https://doi.org/10.1186/1475-2840-9-24.

5. r Alagona PJ. Beyond LDL cholesterol: the role of elevated triglycerides and low HDL cholesterol in residual CVD risk remaining after statin therapy. Am J Manag Care. 2009;15(3):S65-S73.

6. Barter P. HDL-C: role as a risk modifier. Atheroscler Suppl. 2011;12(3):267-270. Available from: https://doi.org/10.1016/ S1567-5688(11)70885-6.

7. Cziraky MJ, Watson KE, Talbert RL. Targeting low HDLcholesterol to decrease residual cardiovascular risk in the managed care setting. J Manag Care Pharm. 2016;14(8, Suppl):S3-28-S30-31. PMID: 18950252. Available from: https: //doi.org/10.18553/jmcp.2008.14.S8-A.1.

8. Daskalopoulou SS, Mikhailidis DP. Reaching goal in hypercholesterolaemia: dual inhibition of cholesterol synthesis and absorption with simvastatin plus ezetimibe. Curr Med Res Opin. 2006;22(3):511-528. PMID: 16574035. Available from: https://doi.org/10.1185/030079906X89856.

9. Christou GA, Kouidi EJ, Deligiannis AP, Kiortsis DN. Diagnosis and treatment of dyslipidaemias in athletes. Curr Vasc Pharmacol. 2017;15(3):238-247. PMID: 28137212. Available from: https://doi.org/10.2174/1570161115666170127162526.
10. Sorensen SV, Frick KD, Wade A, Simko R, Burge R. Model-based simulation to explore the cost-effectiveness of following practice guidelines for triglyceride and low-density lipoprotein cholesterol control among patients with diabetes mellitus and mixed dyslipidemia. Clin Ther. 2009;31(4):862-879. PMID: 19446159. Available from: https://doi.org/10.1016/j.clinthera. 2009.04.015.

11. Abdel-Maksoud M, Sazonov V, Gutkin SW, Hokanson JE. Effects of modifying triglycerides and triglyceride-rich lipoproteins on cardiovascular outcomes. J Cardiovasc Pharmacol. 2008;51(4):331-351. PMID: 18427276. Available from: https: //doi.org/10.1097/FJC.0b013e318165e2e7.

12. Tenenbaum A, Fisman EZ. Fibrates are an essential part of modern anti-dyslipidemic arsenal: spotlight on atherogenic dyslipidemia and residual risk reduction. Cardiovasc Diabetol. 2012;11(125). PMID: 23057687. Available from: https://doi. org/10.1186/1475-2840-11- 125 .

13. Didur MD. Possibilities of metabolics use in practice of sports medicine and physical rehabilitation on the example of Elkar. Saint-Petersburg. 2007;p. 32.

14. Mielgo-Ayuso J, Maroto-Sánchez B, Luzardo-Socorro R, Palacios G, Gil-Antuñano NP. Evaluation of nutritional status and energy expenditure in athletes. Nutr Hosp. 2015;31(Suppl 3):227-236. Available from: doi:10.3305/nh.2015.31.sup3.8770.

15. Poli A, Visioli F. Pharmacology of Nutraceuticals with Lipid Lowering Properties. High Blood Press Cardiovasc Prev. 2019;26(2):113-118. PMID: 30877602. Available from: https: //doi.org/10.1007/s40292-019-00311-x.

16. Zhang $\mathrm{Y}$, Kishi $\mathrm{H}$, Kobayashi S. Add-on therapy with traditional Chinese medicine: An efficacious approach for lipid metabolism disorders. Pharmacol Res. 2018;134:200-211. PMID: 29935947. Available from: https://doi.org/10.1016/j. phrs.2018.06.004.

17. Statsenko EA. Characteristics of lipid peroxidation and markers of endogenous intoxication in monitoring physical loads during rower training. Vopr Kurortol Fizioter Lech Fiz Kult. 2011;(3):41-45.

18. Tappy L, Rosset R. Fructose Metabolism from a Functional Perspective: Implications for Athletes. Sports Med. 2017;47(Suppl 1):23-32. PMID: 28332117. Available from: https://doi.org/10.1007/s40279-017-0692-4.

19. Martusevich AK, Karuzin KA. The influence of invidialized vitamin and mineral complex on some parameters of working capacity and oxidative metabolism in sportsman. Gerald New Med Tech. 2015;22(4):127-132. Available from: https: //doi.org/10.12737/17037.

20. Martusevich AK, Karuzin KA. Cohort study of microelement status in "healthy" population of Russian megapolis. Biomedicine (Taiwan). 2019;9(3):e142. PMID: 31453796. Available from: https://doi.org/10.1051/bmdcn/2019090315.

21. Martusevich AK, Karuzin KA, Larionov AL. Blood Trace Elements under Personalized Metabolic Correction: The Preliminary Data. Journal of Pharmaceutical Sciences and Research. 2020;12(5):680-683.

22. Gubler EV, Genkin AA. Application of nonparametric statistical criteria in biomedical research. Saint-Petersburg. 2003;p. 141.

23. Gilev GA, Kulinenkov OS, Savostjanov MV. Pharmacological support of sportsman trainings. Moscow: MGIU. 2007;224.

24. Kukes VT, Gorodetsky VV. Sports pharmacology. Advances, problems, perspectives. Sports medicine: science and practice. $2011 ;(1): 12-15$. 